\title{
Fuzzy logic-based energy management strategy for a novel mechatronics-electro-hydraulic power coupling electric vehicle
}

Jian Yang

Qingdao University https://orcid.org/0000-0002-7934-488X

Tiezhu Zhang

Qingdao University

Jichao Hong ( $\nabla$ qdbithong@163.com )

University of Science and Technology Beijing https://orcid.org/0000-0001-5265-3466

Hongxin Zhang

Qingdao University

Qinghai Zhao

Qingdao University

Zewen Meng

Qingdao University

\section{Original Article}

Keywords: Mechatronics-electro-hydraulic power coupling electric vehicle, Economic performance, Energy efficiency, Torque characteristic, Fuzzy control

Posted Date: August 13th, 2021

DOl: https://doi.org/10.21203/rs.3.rs-793390/v1

License: (c) (i) This work is licensed under a Creative Commons Attribution 4.0 International License.

Read Full License 


\section{Title page}

\section{Fuzzy logic-based energy management strategy for a novel mechatronics-electro-hydraulic power coupling electric vehicle}

Jian Yang, born in 1996, received the B.S. degree in vehicle engineering from Liaocheng University, Shandong, China, in 2015. He is current studying for the M.S. degree in vehicle engineering at Qingdao University, Shandong, China. His current research interests include energy management strategies for electro-hydraulic hybrid electric vehicles.

Tel: 15610509093; E-mail: yangxiaoming8533@163.com

Tie-Zhu Zhang, born in 1960, is an academician of the Georgian and Russian Academies of Natural Sciences, and he was once the president of Shandong University of Technology, China.

E-mail: zhangtz@sdut.edu.cn

Ji-Chao Hong, born in 1989, is an associated professor of the School of Mechanical Engineering, University of Science and Technology Beijing, China. He received his PhD degree from Beijing Institute of Technology, China, in 2020. His research areas include big data analysis, fault diagnosis and prognosis of battery systems and fuel cell systems.

E-mail: qdbithong@,163.com

Hong-Xin Zhang, born in 1969, is the dean of the School of Mechanical and Electrical Engineering, Qingdao University, China. E-mail: qduzhx@126.com

Qing-Hai Zhao, born in 1985, is currently a professor at Qingdao University, China. He received his PhD degree from Beijing Institute of Technology, China.

E-mail: zqhbit@163.com

Ze-Wen Meng, born in 1996, is current studying for the M.S. degree in vehicle engineering at Qingdao University, Shandong, China. His research interests include energy management strategies for electro-hydraulic hybrid electric vehicles.

E-mail: mengzewen2020@163.com

\section{Corresponding author: Ji-Chao Hong E-mail: qdbithong@163.com Hong-Xin Zhang E-mail: qduzhx@126.com}




\title{
Fuzzy logic-based energy management strategy for a novel
}

\section{mechatronics-electro-hydraulic power coupling electric vehicle}

\author{
Jian Yang ${ }^{1,2}$ • Tie-Zhu Zhang, ${ }^{1,2}$ Ji-Chao Hong ${ }^{3,}$ • Hong-Xin Zhang, ${ }^{1,{ }^{*}} \cdot$ Qing-Hai Zhao ${ }^{1,2}$ • Ze-Wen Meng ${ }^{1,2}$
}

\begin{abstract}
In order to solve the troubles of electric peak torque and enhance the energy efficiency of electric vehicles, a novel mechatronics-electro-hydraulic power coupling electric vehicle (MEH-PCEV) with low energy consumption is proposed. The hydraulic system and the motor are integrated into a device to simplify the structure, taking the pure electric vehicle as a reference. Simultaneously, a fuzzy logic-based optimization method is proposed for real-time adjustment of the electric torque based on the original rule control strategy. Compared with the pure electric vehicle, the proposed methods can substantially enhance energy utilization and the recovery efficiency of electric energy. Ultimately, the actual driving cycle is analyzed using data acquisition capacity, with the authentic speed as the input signal. The verification results on real-world vehicles demonstrate the consumption rate of the battery state of charge and the electric torque are improved by $7.32 \%$ and reduced by $22.24 \%$, respectively. Moreover, this research is expected to provide a reference for the development and engineering applications of the mechatronics-electro-hydraulic coupling systems.
\end{abstract}

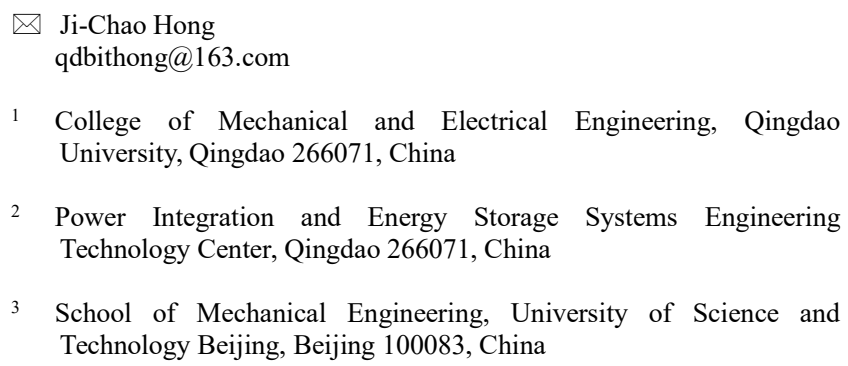

Keywords: Mechatronics-electro-hydraulic power coupling electric vehicle - Economic performance - Energy efficiency • Torque characteristic $\bullet$ Fuzzy control

\section{Introduction}

\subsection{Research motivation}

With the increase of energy-saving and environmental protection requirements, pure electric vehicles (PEV) are developing rapidly [1-2]. Whereas constrained by battery defects, the frequent start/stop of the PEV generates peak torque [3]. The battery's life and vehicle mileage will be substantially reduced [4]. In recent years, electro-hydraulic hybrid technology has received a lot of attention as a new configuration. The hydraulic system has the advantages of high power density [5-6] and fast energy charging and discharging [7-8].

\subsection{Literature review}

New energy vehicles are regarded as a promising means of transportation to reduce air pollution and fossil fuel consumptions. Nevertheless, on the one hand, voltage, temperature, and state of charge (SOC) are the essential characterization parameters for various battery faults, and accurate prediction of these parameters is critical for battery safety [9]. On the other hand, battery safety and vehicle mileage are obstacles to the development of electric vehicles [10]. Therefore, pure electric automobile research is far from ample to enhance energy efficiency 
and driving range.

Currently, researchers have done a lot of work on hybrid research. Zhu [11] built a complex multi-energy coupled system to improve the traction power supply system's overall energy efficiency. Liu [12] presented an electro-hydraulic hybrid power system and verified its energy recovery efficiency of up to $50 \%$. The new mechanical-electric-hydraulic dynamic coupling drive system (MEH-DCDS) can combine a conventional permanent magnet motor with a swashplate piston pump/motor to achieve the mutual transformation of electrical, mechanical, and hydraulic energy [13]. MEH-DCDS plays a significant role in supporting the development of electro-hydraulic hybrid technologies, which will gradually improve the production and lifestyle of the human.

For multi-mode hybrid vehicles, the core technology is the design of the control strategy [14]. The rule-based control strategy is highly logical. Whereas the output signal changes in real-time in different environments [16-17]. Yang [18] proposed a novel electro-mechanical-hydraulic coupler. After a theoretical analysis of the system power flow, a rule-based dynamic optimal energy management strategy was established to control energy distribution and the dynamic switching of working modes in real-time. Ultimately, a fuzzy controller was used to optimize the logic threshold control strategy. The motor torque was dramatically reduced and the overall efficiency of the motor operating point was enhanced. Chen [19] proposed a rule-based dynamic optimal energy management strategy for city buses. The outcomes demonstrated that the peak torque was reduced through $36.4 \%$, and the battery consumption was decreased via $33.98 \%$ in the new European driving conditions. Xiong [20] used both fuzzy control strategy and parallel drive energy management to control the bus. After verification, the energy consumption was theoretically $30.3 \%$ lower than that of conventional buses under driving cycle working conditions. Tirkolaee [21] combined the interactive fuzzy-based solution method with the adaptive artificial fish swarm algorithm, aiming to find the optimal solution for the test object.

Currently, intelligent control strategy has better control effect on nonlinear hybrid drive systems. Therefore, this paper presents a fuzzy logic control strategy for real-time adjustment of the electric torque proportionality coefficient for mechatronics-electro-hydraulic power coupling electric vehicles (MEH-PCEV). Simultaneously, the actual vehicle data acquisition method is further used to carry out the test verification.

\subsection{Challenges and Problems}

Hydraulic technology has made great progress in the conversion of mechanical energy into hydraulic energy [22]. Nevertheless, the development of mechatronic technology first faces some challenges that cannot be ignored, mainly reflected in the volume loss and mechanical loss. To continuously expand its field of application to meet future needs, it is vital to begin with the discount of internal stress losses in elements and the use of hydrostatic technology with load sensing systems [23-24]. Second, electro-hydraulic servo-proportional technology as well as computer simulation standardization is the core technology to improve its working reliability [25]. Electro-hydraulic torque coupling and the adoption of a generalized control mechanism are also issues that need to be explored in the future.

Fuzzy control language is simple and robust with high fault tolerance [26]. However, Simple information processing will lead to lower control accuracy and poor dynamic quality. Furthermore, fuzzy controller design lacks systematicity to define control objectives [27].

Currently, there are many studies that use real measurement data to construct vehicle driving conditions. Whereas there are fewer articles that import actual driving cycles into simulation models for validation. Simultaneously, due to incorrect driver operation, vehicle vibration, and road complications, the car generates noise that causes data to appear as a singularity. A giant variety of evaluation strategies nonetheless have many difficulties in smoothing the speed curve. Due to the inherent drawbacks of the method and the above challenges, there are nevertheless sizable difficulties in the sensible mannequin validation [28].

\subsection{Contributions of this work}

To address the above issues, the main research of this paper has the following points:

1)A novel mechatronics-electro-hydraulic power coupling system is proposed.

2)A fuzzy logic-based optimization strategy is proposed for real-time adjustment of the electric torque.

3) The actual results of driving conditions are analyzed by means of data acquisition and simulation. 


\subsection{Organization of the paper}

The rest of this paper is organized as follows: Section 2 describes the working principle of the MEH-PCEV. Section 3 performs the design and modeling of the fuzzy controller. Section 4 collects real road information for verification. Section 5 summarizes the research of this paper.

\section{Working principle of the MEH-PCEV}

The specific structure of the MEH-PCEV is given in Fig. 1. MEHC-PCEV is a new vehicle type based on pure electric drive [29-30]. The system includes a high pressure accumulator (HPA), a low pressure accumulator (LPA), safety valves, oil coolers, oil filters, solenoid valves, mechatronics-electro-hydraulic power coupling system (MEH-PCS), clutches, main reducers, differentials, pressure sensors, controllers, power converters, and battery.

To reduce the electric peak torque, the vehicle is customarily started using hydraulic power. In this case, hydraulic energy is converted to mechanical energy. When the vehicle accelerates or climbs a hill, the demand torque must be high enough. Thus, the battery pack begins to provide electrical power. Electric energy is coupled with hydraulic energy through the MEH-PCS, and then mechanical energy is output. The motor provides power when the external load of the vehicle is small relative to the starting and acceleration working conditions. At this time, the solenoid valve switch is closed and the hydraulic system does not work. When the vehicle is braking, the regenerative braking energy is converted into hydraulic energy and recycled into the HPA. The remaining energy is converted into electrical energy through the generator and stored in the battery.

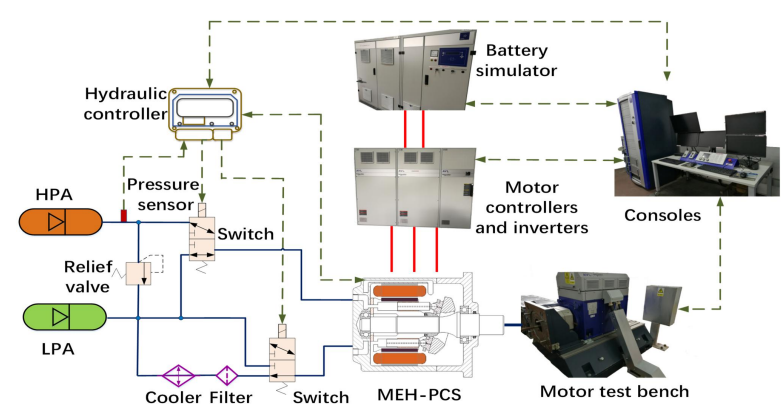

Figure 1 Specific structure of the MEH-PCEV

\section{Design and modeling of fuzzy controllers}

Fuzzy logic control strategy is also a rule-based control strategy. It does not rely on an exact mathematical model, and the control rules are mainly based on engineering experience. The strategy has a strong robustness to the parameter changes of the controlled object and a strong ability to exclude the external disturbances. Therefore, fuzzy logic energy control strategies have shown promising applications in the field of hybrid vehicles [31-34]. The control strategy consists of three parts: fuzzification, fuzzy inference, and defuzzification. The composition of the fuzzy controller is demonstrated in Fig. 2.

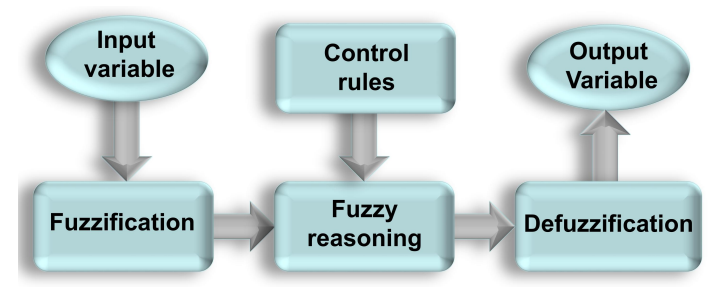

Figure 2 Composition of the fuzzy controller

\subsection{Fuzzification of Precise Quantities}

Fuzzy conclusions are generated by reasoning operations on values using fuzzy logic [35]. Therefore, the first step is to convert the exact input quantities into fuzzy values, which is the fuzzification of precise quantities. According to the driving cycle situation and the rule control strategy, the vehicle speed $(v)$ and the pressure difference of the accumulator $(\Delta p)$ are designed as the system's input variables. Eq. (1) represents the pressure difference equation of the accumulator. First, the input variables of the processing system should be discretized. Second, the linguistic variables are determined. Generally, the symbols "M" and "B" can be used to describe them. In this paper, the fuzzy set of $v$ is $\{\mathrm{NB}, \mathrm{NS}, \mathrm{ZO}, \mathrm{PS}, \mathrm{PB}\}$, and the fuzzy domain is $[0,25]$. $\{\mathrm{NB}, \mathrm{NS}, \mathrm{ZO}, \mathrm{PS}, \mathrm{PB}\}$ is the fuzzy set of $\Delta p$, and $[0,350]$ is its fuzzy domain. NB represents negative large, NS represents negative small, Z0 represents zero, PS represents positive small, and PB represents positive large. Ultimately, this paper chooses the Gaussian shape's affiliation function, which can be expressed by Eq. (2). Fig. 3 and Fig. 4 indicate membership functions of input variables, respectively.

$$
\begin{aligned}
& \Delta p=\text { PHPA-PLPA } \\
& f(x, \sigma, a)=e^{-\frac{(x-a)}{\left(2 \sigma^{2}\right)}}
\end{aligned}
$$

where PHPA represents the pressure of the high pressure accumulator. The pressure of the low pressure 
accumulator is PLPA. $a$ is used to determine the center of the function and $\sigma$ is used to determine the width of the curve.

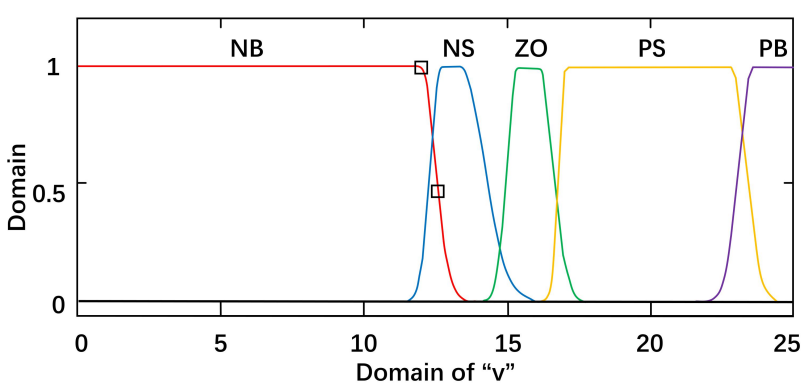

Figure 3 Membership function of "v"

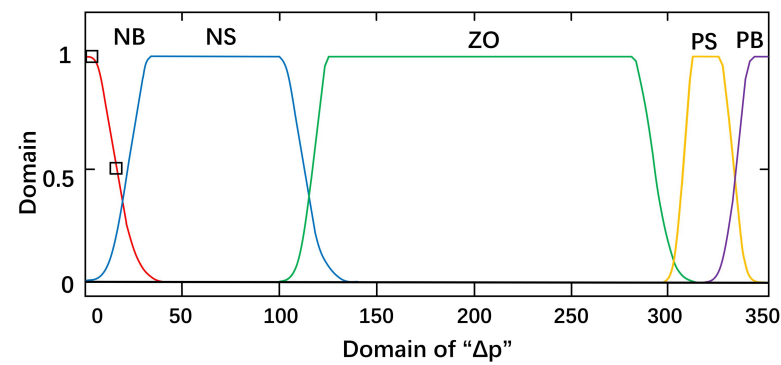

Figure 4 Membership function of " $\Delta p$ "

\subsection{Fuzzy Inference and Rules}

Fuzzy control rules are the core of the fuzzy controller [36]. The purpose of fuzzy rules is to achieve conversion between input and output variables. In the process of establishing fuzzy control rules, when the system has a large error, a larger control amount is used to eliminate the error as soon as possible. When a smaller error occurs in the system, an appropriate control amount is used to prevent overshooting and maintain system stability [37]. The development of the rules requires abundant experience. Fig. 5 portrays the output map of the fuzzy inference system.

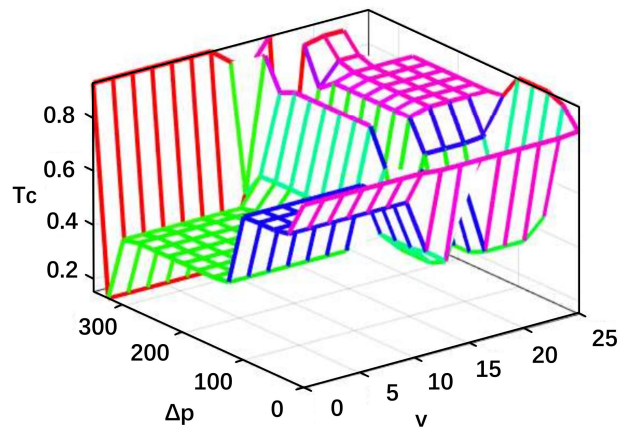

Figure 5 Output map of the fuzzy inference system

\subsection{Defuzzification of Fuzzy Quantities}

The output quantity derived from the fuzzy controller is a subordinate function or fuzzy subset which reflects the fuzziness of the original control language. A defuzzification verdict is needed for these fuzzy outputs to transform them into an accurate control quantity. Thus, the role of defuzzification is to map the fuzzy set to a definite point [38-39]. The scale factor of electric torque $\left(T_{\mathrm{c}}\right)$ is used as the output variable, and the triangle function is selected as the output variable's membership function, as demonstrated in Fig. 6. Its fuzzy set is $\{\mathrm{NB}, \mathrm{NS}, \mathrm{ZO}, \mathrm{PS}$, $\mathrm{PB}\}$, and the fuzzy domain is $[0,1]$.

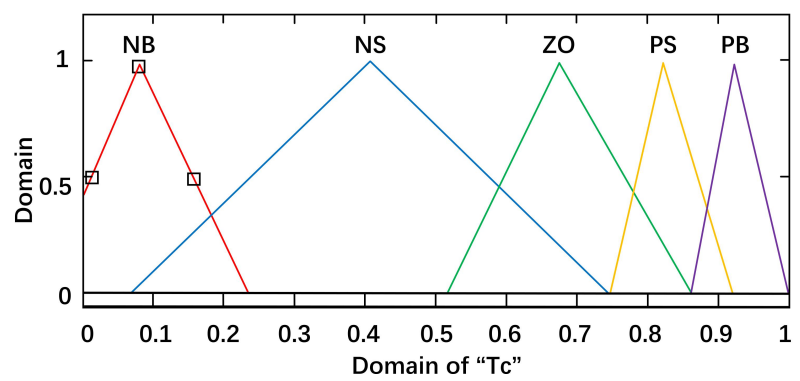

Figure 6 Membership function of " $T_{\mathrm{c}}$ "

\subsection{Modeling of fuzzy controllers}

The model is based on the Fuzzy Logic Controller module in Simulink [40-43]. The article inputs the fuzzy controller file or structural data and outputs the desired value through the fuzzy control box as expressed in Fig. 7.

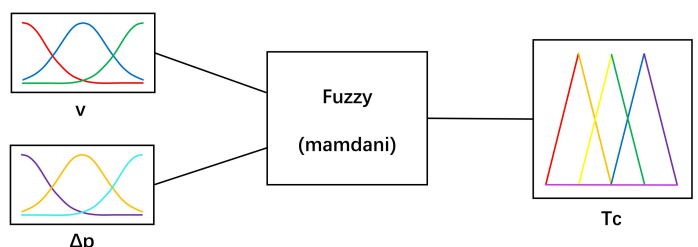

Figure 7 Fuzzy controller module

When the vehicle enters electrodynamic drive mode (ED mode), the vehicle's external load is relatively low. At this time, the traction force only needs to overcome frictional resistance and gradient resistance. Therefore, the acceleration signal $(a c c)$ is multiplied by the external characteristic curve of the motor to obtain the motor torque.

$$
T \cdot a c c=T_{\mathrm{m}}
$$

where $T_{\mathrm{m}}$ indicates the actual torque signal of the motor. 


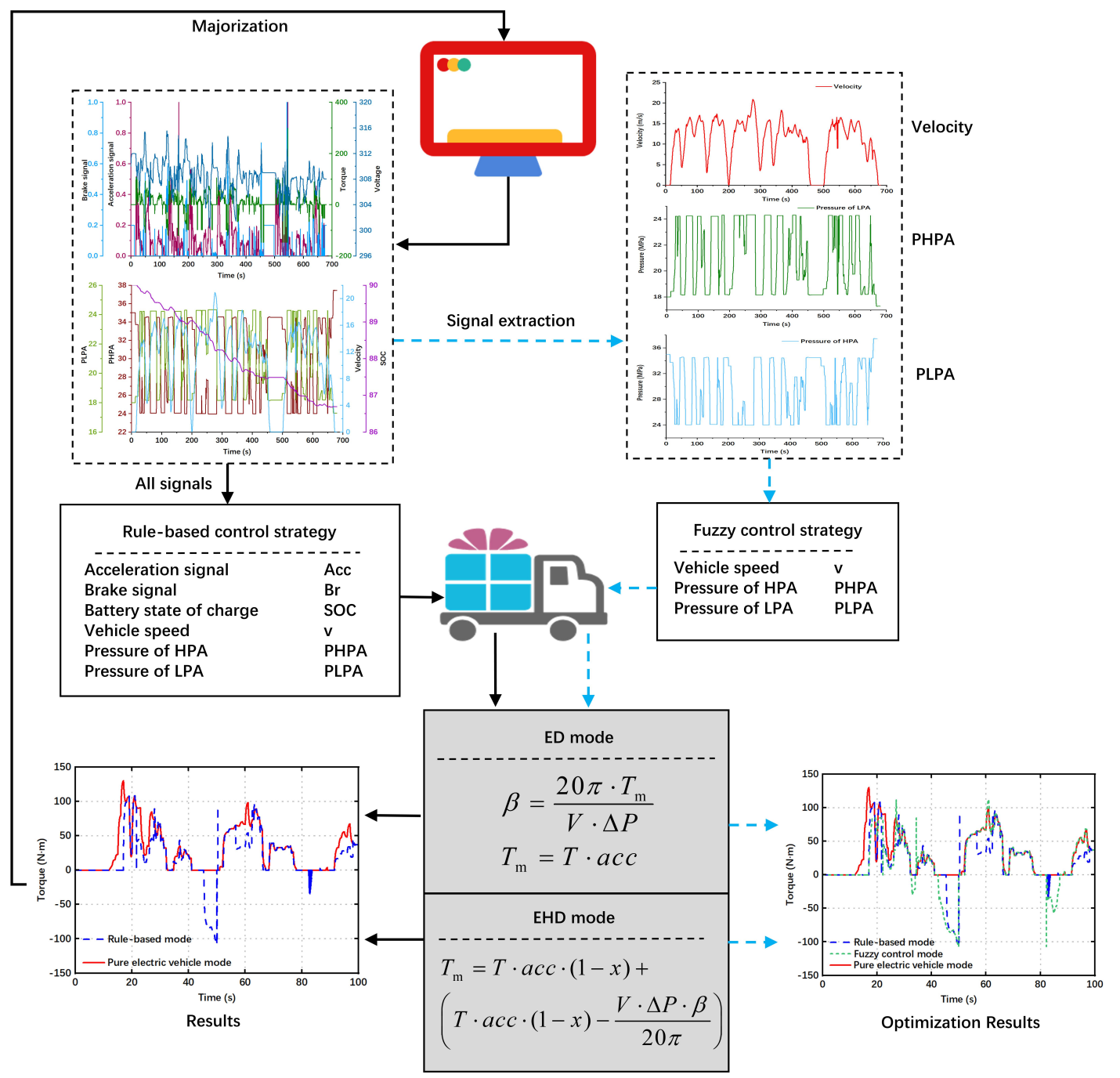

Figure 8 Control strategy of the MEH-PCEV

When the vehicle enters into electro-hydraulic drive mode (EHD mode), electric and hydraulic energy together provide power, and their distribution ratio is set to $x$ and $(1-x)$. The torque of the motor is the acceleration signal multiplied by the motor's external characteristic curve. Themotor torque at this point is then calculated as the swashplate angle according to the distribution ratio:

$$
\beta=\frac{20 \pi \cdot T_{\mathrm{m}}}{V \cdot \Delta p}
$$

where $\Delta p$ is the differential pressure between the inlet and outlet of the secondary element. $V$ is the displacement of the secondary element. $\beta$ indicates the swashplate opening.
Subsequently, it follows from the above equation that:

$$
\beta=\frac{T \cdot a c c \cdot x \cdot 20 \pi}{V \cdot \Delta p}
$$

When the hydraulic power cannot meet the power demand, the electric power will provide the power compensation. Motor torque can be calculated by Eq. (6):

$$
T_{\mathrm{m}}=T \cdot a c c \cdot(1-x)+\left(T \cdot a c c \cdot(1-x)-\frac{V \cdot \Delta P \cdot \beta}{20 \pi}\right)
$$

The electrical torque signal is fuzzy controlled and then 


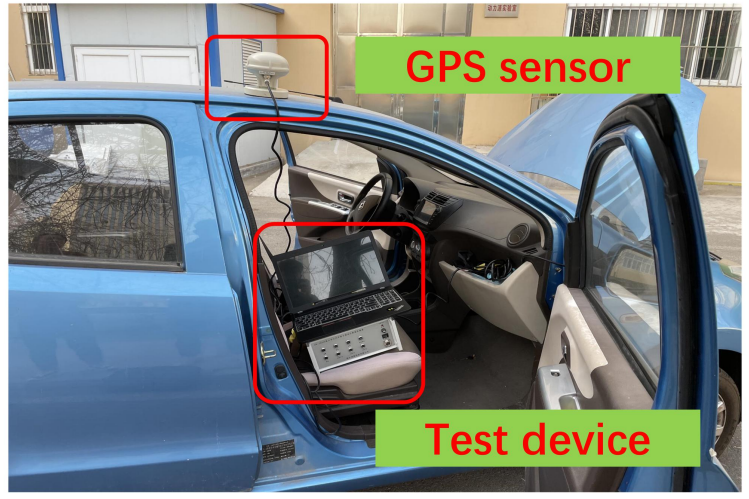

(a)

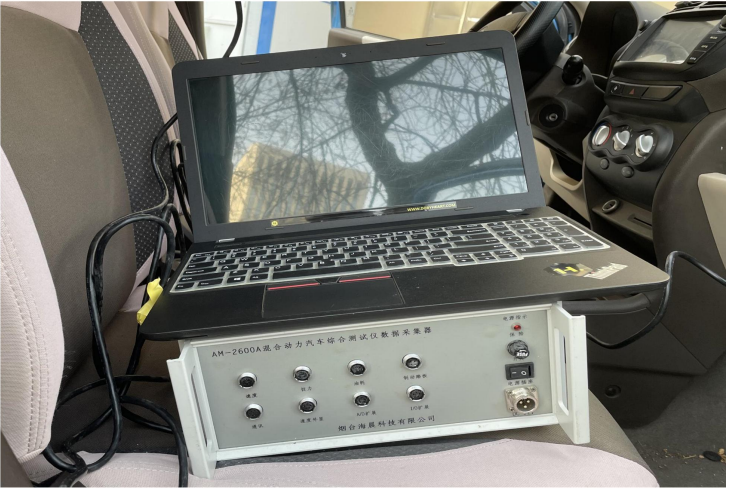

(b)

Figure 9 Test equipments: (a) Test vehicle (b) Data tester

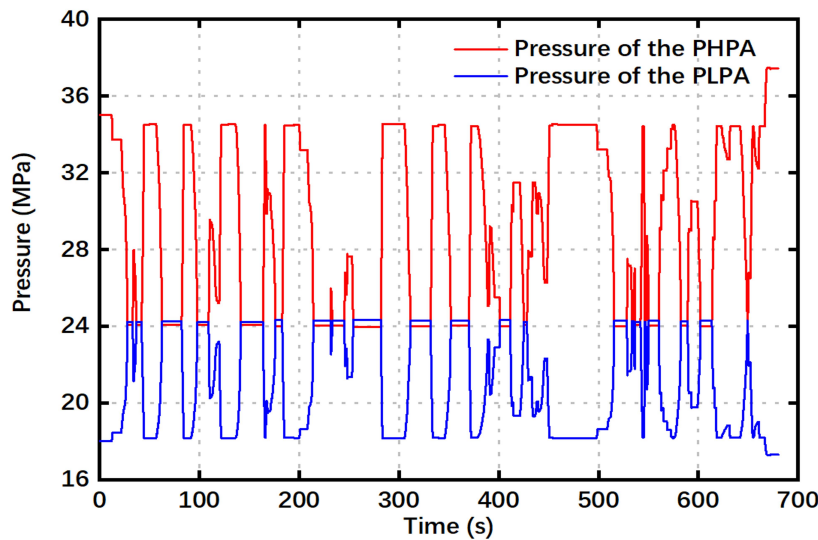

(a)

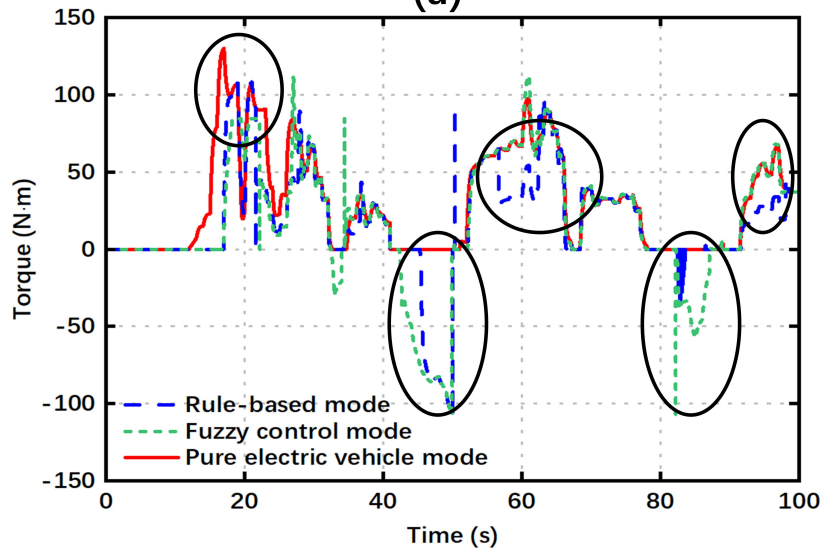

(c)

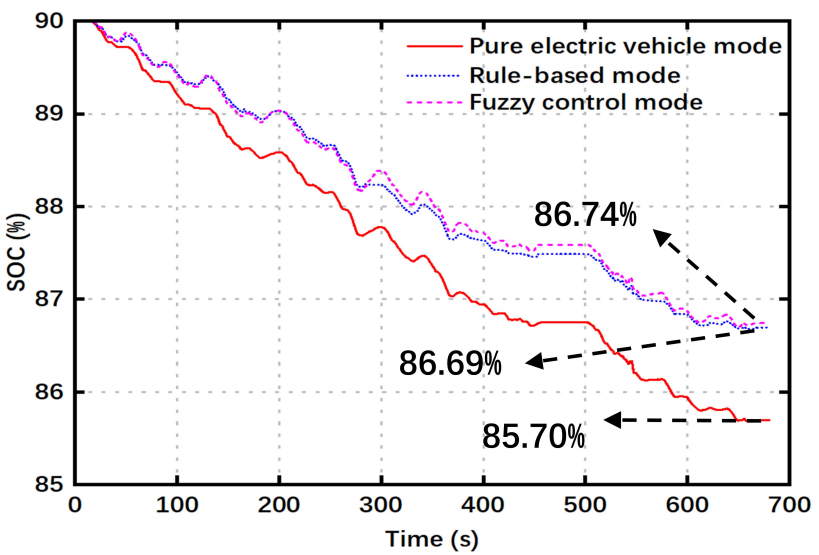

(b)

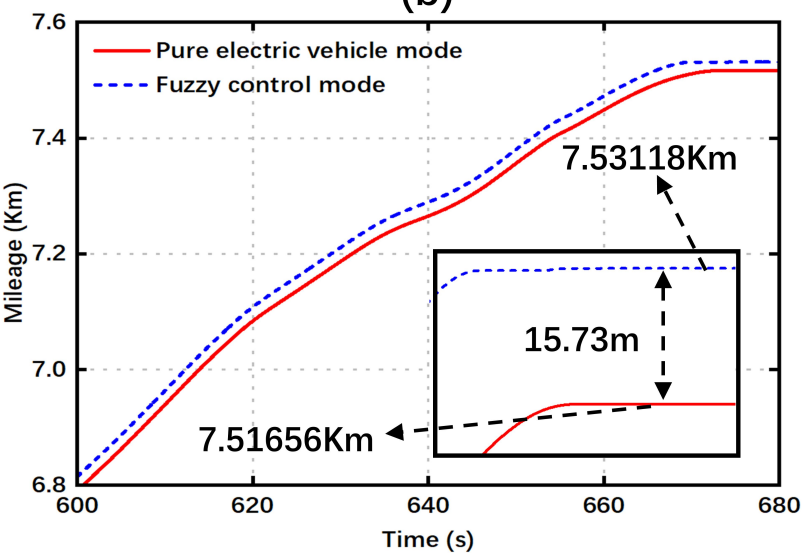

(d)

Figure 11 Analysis of experimental results: (a) Hydraulic pressure variation (b) Changes in battery SOC (c) electric torque variation (d) vehicle mileage variation 
connected to the mode selection module. The fuzzy control strategy models for ED mode and EHD mode are presented in Fig. 8. As can be seen from the figure, based on the regular control strategy, the electrical torque will be output only after fuzzy adjustment.

\section{Validation Under Actual Driving Conditions}

Typical cycling conditions must be obtained from traffic data on the vehicle's route. In order to construct a realistic vehicle driving cycle, representative roads in Qingdao were selected for further study in this study. By analyzing the utilization rate of each road, geographic information characteristics, and traffic flow of each road, this paper selected representative routes in urban and suburban areas,

mainly passing through densely populated residential areas and densely populated vehicle lots [44-45].

After the route is determined, it is essential to select the appropriate test equipment and check communication status to ensure the accuracy of data collection. Test equipment include GPS sensor, laptop, AM-2600 tester, signal connection cables, stopwatch, and power supply, as demonstrated in Fig. 9.

Table 1 Basic parameters of the MEH-PCEV

\begin{tabular}{lcc}
\hline Components & Parameters & Value \\
\hline & Loaded mass $(m)$ & $1206 \mathrm{~kg}$ \\
Vehicle basic & Rolling resistance coefficient $(f)$ & 0.0135 \\
parameters & Coefficient of air resistance $\left(C_{\mathrm{D}}\right)$ & 0.32 \\
& Wheel width $(D)$ & $290 \mathrm{~mm}$ \\
High pressure & Transmission efficiency $(\eta)$ & 0.85 \\
accumulator & Work pressure $(P)$ & $35 \mathrm{MPa}$ \\
Low pressure & Volume $(L)$ & $35 \mathrm{~L}$ \\
accumulator & Work pressure $(P)$ & $18 \mathrm{MPa}$ \\
& Volume $(L)$ & $35 \mathrm{~L}$ \\
Battery & Voltage $\left(V_{\mathrm{b}}\right)$ & $310 \mathrm{~V}$ \\
& Maximum power $\left(P_{\mathrm{b}}\right)$ & $35 \mathrm{~kW}$ \\
Secondary & Pack capacity $(C)$ & $65 \mathrm{Ah}$ \\
component & Displacement $(V)$ & $30 \mathrm{ml} / \mathrm{r}$ \\
Motor & Swash-plate opening $(\beta)$ & $-1 \leq \beta \leq 1$ \\
\hline
\end{tabular}

During data collection, the car will generate noise due to the driver's incorrect operation, vehicle vibration, and the road conditions, which will cause singularities in the data and affect the accuracy of the final experiment. Therefore, for a large amount of data, this paper intercepts $680 \mathrm{~s}$ of them for analysis. The basic parameters are illustrated in Table 1.

Path following curves are depicted in Fig. 10. After analysis, it can be seen that the actual vehicle speed curve of the MEH-PCEV basically overlaps with the control speed curve. The result illustrates that the strategy is highly reliable in the actual cyclic mode.

Fig. 11 (a) accentuates the oil pressure curves of the high and low pressure accumulators. The pressure curve changes continuously, and the PHPA decreases whilst the PLPA increases. The simulation effects demonstrate that hydraulic power can play a full position in the process of vehicle operation.

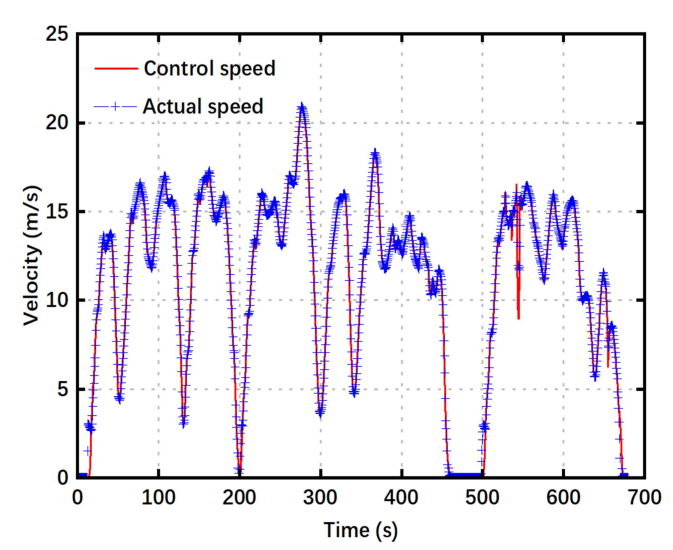

Figure 10 Comparison of the vehicle speed

The battery state of charge is a basic indicator of the remaining battery power and plays an essential role in the battery's optimal operation [46-47]. Fig. 11 (b) displays the variation curve of the battery charge. The SOC of the car with an embedded fuzzy control strategy was $86.74 \%$. The battery SOC of pure electric vehicles is $85.70 \%$. $86.69 \%$ is the battery SOC based on rule-based control strategy. The vehicle consumes $7.32 \%$ less battery than a pure electric vehicle after fuzzy control. Compared with the rule-based control strategy, the fuzzy control strategy reduced the vehicle's battery consumption rate by $1.51 \%$. 
The validation results portray that this strategy can substantially improve energy efficiency.

Fig. 11 (c) displays the comparison of electric torque in 3 modes. As can be seen from the figure, both the rule control strategy and the fuzzy control strategy can substantially reduce the vehicle's peak torque. And it can increase the power recovery in a large proportion. In addition, the effect is even more obvious after fuzzy control. The maximum electric peak power is $22.24 \%$ lower after fuzzy control compared to pure electric vehicles. Therefore, this strategy can effectively reduce the peak torque and increase the utilization of electrical energy.

Fig. 11 (d) presents the graph of vehicle mileage. The mileage of the vehicle after optimization is $7.53118 \mathrm{~km}$. Compared to pure electric vehicles, fuzzy control strategy can effectively increase the vehicle mileage.

\section{Conclusion}

The article proposed a novel low-energy mechatronics-electro-hydraulic power coupling electric vehicle (MEH-PCEV), which combines a conventional motor and a piston pump/motor into a single unit that converts electrical, mechanical, and hydraulic power into a single unit.

Firstly, a fuzzy logic optimization strategy was proposed for the MEH-PCEV configuration, by taking the electric torque as reference. The state of charge, differential pressure, and energy storage of the battery are monitored in real-time, with the desired speed as the manipulate input signal. Based on the real-time control of the velocity threshold and differential pressure threshold, the fuzzy strategy ensures that the output torque meets the vehicle torque necessities. Electrical torque can be adjusted in real-time during operation in accordance to the scaling coefficient.

Secondly, to verify the accuracy and authenticity of the method, the GPS dynamic data acquisition instrument was assembled on the automobile for data acquisition. Through the verification experiment of actual data, the actual speed curve of MEH-PCEV essentially coincides with the control speed curve, indicating that the path following accuracy is higher. The energy consumption of the battery charging state diminished via $7.32 \%$, and the electric torque decreased by $22.24 \%$. The results demonstrated that the fuzzy logic strategy can effectively reduce the peak torque and amplify the energy utilization rate.

This technology provides ideas for the future development and optimization of electro-mechanical-hydraulic power coupled electric vehicles. The future work will focus on two areas: a further verification of the MEH-PCEV's management strategy will be unfolded thru the dSPACE platform; a MEH-PCS device will be embedded into the complete vehicle for operational research of the actual vehicle.

\section{Nomenclature}

\begin{tabular}{|c|c|}
\hline$\Delta p$ & The pressure difference of the accumulator \\
\hline$v$ & The vehicle speed \\
\hline$a$ & The center of the function \\
\hline$\sigma$ & The width of the curve \\
\hline$T$ & The motor torque \\
\hline$T_{\mathrm{c}}$ & The electric torque \\
\hline$T_{\mathrm{m}}$ & The actual torque signal \\
\hline$a c c$ & The acceleration signal \\
\hline$b r$ & The brake signal \\
\hline$\beta$ & The swashplate angle \\
\hline$V$ & The displacement of the secondary element \\
\hline$f$ & The rolling resistance coefficient \\
\hline$m$ & The loaded mass \\
\hline$A$ & The frontal area \\
\hline$D$ & The wheel width \\
\hline$C_{\mathrm{D}}$ & The coefficient of air resistance \\
\hline$\eta$ & The transmission efficiency \\
\hline$P$ & The work pressure of accumulator \\
\hline$L$ & The volume of accumulator \\
\hline$V_{\mathrm{b}}$ & The battery voltage \\
\hline$P_{\mathrm{b}}$ & The battery maximum power \\
\hline$C$ & The battery pack capacity \\
\hline$P_{\mathrm{t}}$ & The motor rated power \\
\hline NB & Negative large \\
\hline NS & Negative small \\
\hline $\mathrm{ZO}$ & Zero \\
\hline PS & Positive small \\
\hline PB & Positive large \\
\hline NB & Negative large \\
\hline MEH-PCS & $\begin{array}{l}\text { Mechatronics-electro-hydraulic } \\
\text { coupling system }\end{array}$ \\
\hline MEH-PCEV & $\begin{array}{l}\text { Mechatronics-electro-hydraulic } \\
\text { coupling electric vehicle }\end{array}$ \\
\hline PEV & Pure electric vehicle \\
\hline HPA & High pressure accumulator \\
\hline LPA & Low pressure accumulator \\
\hline PHPA & Pressure of the high pressure accumulator \\
\hline PLPA & Pressure of the low pressure accumulator \\
\hline EHD & Electro-hydraulic drive \\
\hline HD & Hydrodynamic drive \\
\hline MB & Mechanical brake \\
\hline ERB & Electric regenerative braking \\
\hline $\mathrm{HRB}$ & Hydraulic regenerative braking \\
\hline
\end{tabular}




\begin{tabular}{ll}
\hline ED & Electrodynamic drive \\
SOC & State of charge \\
HPA & High pressure accumulators \\
LPA & Low pressure accumulators
\end{tabular}

\section{Declaration}

\section{Acknowledgements}

The authors sincerely thanks to Professor Hong-Xin Zhang of Qingdao University and Professor Ji-Chao Hong of University of Science and Technology Beijing for his critical discussion and reading during manuscript preparation.

\section{Funding}

Supported by National Natural Science Foundation of China (Grant No. 52075278), Postdoctoral Science Foundation Project of China (2021M690353), Municipal Livelihood Science and Technology Project of Qingdao (Grant No. 19-6-1-92-nsh),

\section{Availability of data and materials}

The datasets supporting the conclusions of this article are included within the article.

\section{Authors' contributions}

The author' contributions are as follows: Tie-Zhu Zhang, Hong-Xin Zhang, and Ji-Chao Hong were in charge of the whole trial; Jian Yang wrote the manuscript; Qing-Hai Zhao and Ze-Wen Meng assisted with sampling and laboratory analyses.

\section{Competing interests}

The authors declare no competing financial interests.

\section{Consent for publication}

Not applicable

\section{Ethics approval and consent to participate}

Not applicable

\section{References}

[1] C Qiu, K T Chau, C T Wood, et al. Overview of Wireless Charging Technologies for Electric Vehicles. Journal of Asian Electric Vehicles, 2014, 12(1):1679-1685.

[2] Y Zhang, G Chen, Y Hu, et al. Cascaded multilevel inverter based power and signal multiplex transmission for electric vehicles. CES Transactions on Electrical Machines and Systems, 2020, 4(2):123-129.

[3] X Wang, J Chen, S Quan, et al. Hierarchical model predictive control via deep learning vehicle speed predictions for oxygen stoichiometry regulation of fuel cells. Applied Energy, 2020, 276:115460.
[4] J Hong, Z Wang, Y Yao. Fault prognosis of battery system based on accurate voltage abnormity prognosis using long short-term memory neural networks. Applied Energy, 2019, 251: 113381.

[5] B Xha, A Gx, A Bh, et al. The applications of energy regeneration and conversion technologies based on hydraulic transmission systems: A review. Energy Conversion and Management, 205.

[6] L Xia, Q Long, G Lei, et al. Energy efficiency analysis of integrated drive and energy recuperation system for hydraulic excavator boom. Energy Conversion and Management, 2018, 156:680-687.

[7] H Sun, L Yang, J Jing, et al. Control strategy of hydraulic/electric synergy system in heavy hybrid vehicles. Energy Conversion and Management, 2011, 52(1):668-674.

[8] E Kamal, L Adouane. Hierarchical Energy Optimization Strategy and its Integrated Reliable Battery Fault Management for Hybrid Hydraulic-Electric Vehicle. IEEE Transactions on Vehicular Technology, 2018:3740-3754.

[9] J Hong, Z Wang, W Chen, Y Yao. Synchronous multi-parameter prediction of battery systems on electric vehicles using long short-term memory networks. Applied Energy, 2019, 254: 113648.

[10]J Hong, Z Wang, T Zhang, H Yin, H Zhang, W Huo, Y Zhang, Y Li. Research on Integration Simulation and Balance Control of a Novel Load Isolated Pure Electric Driving System. Energy, 2019, 189: 116220.

[11]F Zhu, Z Yang, F Lin, et al. Synthetic Optimization of Traction Power Parameters and Energy Storage Systems in Urban Rail Transit. Diangong Jishu Xuebao/Transactions of China Electrotechnical Society, 2019, 34(3):579-588.

[12]H Liu, G Chen, C Xie, et al. Research on energy-saving characteristics of battery-powered electric-hydrostatic hydraulic hybrid rail vehicles. Energy, 2020, 205:118079.

[13]J Yang, T Zhang, $\mathrm{H}$ Zhang, et al. Research on the Starting Acceleration Characteristics of a New Mechanical-Electric-Hydraulic Power Coupling Electric Vehicle. Energies, 2020, 13(23):6279.

[14]Z Wang, Z Zheng, Y Li, et al. Modulation and Control Strategy for Electric Traction Drive System of Rail Transit Vehicles. Transactions of China Electrotechnical Society, 2016, 31(24):223-232.

[15]J Hu, B Mei, H Peng, et al. Discretely Variable Speed Ratio Control Strategy for Continuously Variable Transmission System Considering Hydraulic Energy Loss. Energy, 2019, 180(AUG.1):714-727.

[16]Y Yuan, J Zhang. A Novel Initiative Braking System with Nondegraded Fallback Level for ADAS and Autonomous Driving. IEEE TRANSACTIONS ON INDUSTRIAL ELECTRONICS, 2020; 67(6): 360-4370.

[17]Erfan, Babaee, Tirkolaee, et al. A hybrid augmented ant colony optimization for the multi-trip capacitated arc routing problem under fuzzy demands for urban solid waste management. Waste Management \& Research, 2019; 38(2):156-172.

[18]J Yang, T Zhang, J Hong, et al. Research on Driving Control Strategy and Fuzzy Logic Optimization of a Novel Mechatronics-Electro-Hydraulic Power Coupling Electric Vehicle. Energy, 2021, 233(Nov):121221.

[19]G Chen, H Liu. Design and energy utilization of electro-hydrostatic hydraulic hybrid system for battery bus. Proceedings of the Institution of Mechanical Engineers Part D Journal of Automobile Engineering, 2020, 235(2-3):095440702094943.

[20]W Xiong, Z Yong, C Yin. Optimal energy management for a series-parallel hybrid electric bus. Energy Conversion and 
Management, 2009, 50(7):1730-1738.

[21]E B Tirkolaee, A Goli, G W Weber. Fuzzy Mathematical Programming and Self-Adaptive Artificial Fish Swarm Algorithm for Just-in-Time Energy-Aware Flow Shop Scheduling Problem with Outsourcing Option. IEEE Transactions on Fuzzy Systems, 2020.

[22]K Gromaszek, L G Kozlov, V V Bogachuk, et al. Determining of the optimal parameters for a mechatronic hydraulic drive. Photonics Applications in Astronomy, Communications, Industry, and High-Energy Physics Experiments 2018. 2018.

[23]A Maczyszyn. Investigation Method and Mathematical Model of Pressure Losses in Hydraulic Rotary Motor. Nephron Clinical Practice, 2018, 25(1):93-98.

[24]W Wu, H Liu, J Zhou, et al. Energy efficiency of hydraulic regenerative braking for an automobile hydraulic hybrid propulsion method. International Journal of Green Energy, 2019, 16(7):1-8.

[25]H Du, J Wei, J Fang. The design, simulation, and experiment of high-accuracy multi-axle electro-hydraulic control servo steering system. Advances in Mechanical Engineering, 2016, 8(10):8/10/1687814016674383.

[26]P M Marusak. Advantages of an easy to design fuzzy predictive algorithm in control systems of nonlinear chemical reactors. Applied Soft Computing, 2009, 9(3):1111-1125.

[27]S Sorooshian. Fuzzy Approach to Statistical Control Charts. Journal of Applied Mathematics, 2013, (2013-9-26), 2013, 2013(2):4499-4588.

[28]E Ericsson. Independent driving pattern factors and their influence on fuel-use and exhaust emission factors. Transportation Research Part D, 2001, 6(5):325-345.

[29]Y Hao, L Quan, H Cheng, et al. Potential energy directly conversion and utilization methods used for heavy duty lifting machinery1. Energy, 2018, 155(jul.15):242-251.

[30]H He, C Wang, H Jia, et al. An intelligent braking system composed single-pedal and multi-objective optimization neural network braking control strategies for electric vehicle. Applied Energy, 2020, 259.

[31]J Ruan, P D Walker, P A Watterson, et al. The dynamic performance and economic benefit of a blended braking system in a multi-speed battery electric vehicle. Applied Energy, 2016, 183:1240-1258.

[32]F Naseri, E Farjah, T Ghanbari. An Efficient Regenerative Braking System Based on Battery/Supercapacitor for Electric, Hybrid, and Plug-In Hybrid Electric Vehicles with BLDC Motor. IEEE Transactions on Vehicular Technology, 2017, 66(5):3724-3738.

[33]J Ko, S Ko, H Son, et al. Development of Brake System and Regenerative Braking Cooperative Control Algorithm for Automatic-Transmission-Based Hybrid Electric Vehicles. Vehicular Technology IEEE Transactions on, 2015, 64(2):431-440.

[34]W Enang, C Bannister. Modelling and control of hybrid electric vehicles (A comprehensive review). Renewable and Sustainable Energy Reviews, 2017, 74(JUL.):1210-1239.

[35]Y Xin, T Zhang, H Zhang, et al. Fuzzy Logic Optimization of Composite Brake Control Strategy for Load-Isolated Electric Bus. Mathematical Problems in Engineering, 2019, 2019.

[36]H Si, X Shao, W Zhang. Fuzzy rule-based neural appointed-time control for uncertain nonlinear systems with aperiodic samplings. Expert Systems with Applications, 2020.

[37]Q Zhao, H Zhang, Y Xin. Research on Control Strategy of Hydraulic Regenerative Braking of Electrohydraulic Hybrid Electric Vehicles. Mathematical Problems in Engineering, 2021, 2021.

[38]Deepak, Paul, Efstathios, et al. Optimal \$mu \$ -Estimation-Based
Regenerative Braking Strategy for an AWD HEV. IEEE Transactions on Transportation Electrification, 2017.

[39]D Gao, Z Jin, Q Lu. Energy management strategy based on fuzzy logic for a fuel cell hybrid bus. Journal of Power Sources, 2008, 185(1):311-317.

[40]C Long. Research on semi-active suspension control and performance compromise. Chinese Journal of Mechanical Engineering, 38(3), 29-49.

[41]W Chen, L Zhao, H Wang, et al. Parallel Distributed Compensation /H (infinity) Control of Lane-keeping System Based on the Takagi-Sugeno Fuzzy Model. Chinese Journal of Mechanical Engineering, 2020, 33(1):1-13.

[42]H Truong, H V Dao, T C Do, et al. Mapping Fuzzy Energy Management Strategy for PEM Fuel Cell-Battery-Supercapacitor Hybrid Excavator. Energies, 2020, 13.

[43] Yingbo, Huang, Jing, et al. Approximation-Free Control for Vehicle Active Suspensions with Hydraulic Actuator. IEEE Transactions on Industrial Electronics, 2018.

[44]T Li, A Liu, N N Xiong, et al. A Trustworthiness-based Vehicular Recruitment Scheme for Information Collections in Distributed Networked Systems. Information Sciences, 2020.

[45]Y Liu, J Qiao, Y Hu, et al. Determination of Curve Speed Zones for Mountainous Freeways. Mathematical Problems in Engineering, 2020, 2020(5):1-11.

[46]J Tian, R Xiong, W Shen, et al. A comparative study of fractional order models on state of charge estimation for lithium ion batteries. Chinese Journal of Mechanical Engineering, 2020, 33(4):15.

[47]Q Q Yu, R Xiong, L Y Wang, et al. A Comparative Study on Open Circuit Voltage Models for Lithium-ion Batteries. Chinese Journal of Mechanical Engineering, 2018.

\section{Biographical notes}

Jian Yang, born in 1996, received the B.S. degree in vehicle engineering from Liaocheng University, Shandong, China, in 2015. He is current studying for the M.S. degree in vehicle engineering at Qingdao University, Shandong, China. His current research interests include energy management strategies for electro-hydraulic hybrid electric vehicles.

Tel: 15610509093; E-mail: yangxiaoming8533@163.com

Tie-Zhu Zhang, born in 1960, is an academician of the Georgian and Russian Academies of Natural Sciences, and he was once the president of Shandong University of Technology, China.

E-mail: zhangtz@sdut.edu.cn

Ji-Chao Hong, born in 1989, is an associated professor of the School of Mechanical Engineering, University of Science and Technology Beijing, China. He received his $\mathrm{PhD}$ degree from Beijing Institute of Technology, China, in 2020. His research areas include big data analysis, fault diagnosis and prognosis of battery systems and fuel cell systems.

E-mail: qdbithong@163.com

Hong-Xin Zhang, born in 1969, is the dean of the School of Mechanical and Electrical Engineering, Qingdao University, China.

E-mail: qduzhx@126.com

Qing-Hai Zhao, born in 1985, is currently a professor at 
Qingdao University, China. He received his $\mathrm{PhD}$ degree from Beijing Institute of Technology, China.

E-mail: zqhbit@163.com

Ze-Wen Meng, born in 1996, is current studying for the M.S. degree in vehicle engineering at Qingdao University, Shandong, China. His research interests include energy management strategies for electro-hydraulic hybrid electric vehicles.

E-mail: mengzewen2020@163.com 


\section{Supplementary Files}

This is a list of supplementary files associated with this preprint. Click to download.

- GraphicalAbstract.png 